\title{
Student Online Services Consumption: Routine Practices or Mistrust to Digital Service?
}

\author{
Almira R. Bayanova \\ Kazan (Volga region) Federal University, Russia \\ Kazan National Research Technical University named after A.N. Tupolev - KAI, Russia \\ ORCID: 0000-0003-2311-3924 \\ Irina V. Sivova \\ Gzhel State University, Russia \\ ORCID: 0000-0003-1175-6367 \\ Yuliya L. Kamasheva \\ Kazan Innovative University named after V. G. Timiryasov, Russia \\ ORCID: 0000-0002-7695-0155
}

Olga V. Popova

Financial University under the Government of the Russian Federation, Russia

ORCID: 0000-0001-8142-0346

Evgeny V. Semyanov

Russian New University (RosNOU), Russia

ORCID: 0000-0003-1699-6976

Rozalina V. Shagieva

Russian Customs Academy, Russia

ORCID: 0000-0001-8682-0779

Il'dar M. Yusupov

Kazan Innovative University named after V.G. Timiryasov, Russia

ORCID: 0000-0002-4361-6142

\begin{abstract}
The article aims to study the practices of students' use of services in the conditions of digitalization. The leading methods for the study of this problem are the methods of questioning and testing, allowing to make a qualitative analysis of student consumption practices in the conditions of digitization of services. These methods allowed revealing the peculiarities of online consumption practices by students. The authors found that the majority of students who are not actively using online services, to some extent had experience using online services, but almost every tenth of them had negative result. It is established that students are distrustful of new methods to obtain services, especially when it comes to any operations related to money. It is shown that students who do not practice online services have a feeling that the provided online services are of poor quality, and informants are ready to experience some discomfort in exchange for the usual, guaranteed and high quality, in their opinion, service. In addition, students who are not actively using online services note that it is not easy for them to adapt to new technologically advanced things, but the rest of the students believe that they can adapt to innovations, but the way
\end{abstract}




\begin{abstract}
of providing services that is now perceived as traditional one is the most acceptable for them. It is established that the leader in the use of online services is a taxi. This service is used by all students to some extent, followed by the service of food delivery and only then online banking, online shopping and public services. The novelty and originality of the study lies in the fact that the features of consumption practices among students actively practicing online services and avoiding them are revealed. It is established that students who have little recourse to online services are wary of modern services, which is based either on the previous negative experience of use, or on the unsatisfactory experience of friends, believe that those techniques and applications that are now on the market are not optimal for them and the usual methods of obtaining services for them remain more comfortable and familiar, even though more time spent on obtaining a particular service. The practical significance lies in the fact that the data obtained in the work can be used in social psychology, age psychology, labor psychology, management, sociology, as well as for further theoretical development of this issue.
\end{abstract}

Keywords: students, consumption, Internet, e-Commerce

\title{
INTRODUCTION
}

The twenty-first century is a time of breakthrough technologies and enormous changes in all spheres of human life. Every person is faced with the need to use modern technology every day. All spheres of public life have to adapt to the rapidly developing and rapidly changing world around us (Alisov et al., 2018; Cherdymova et al., 2018; Radaev, Kotelnikova \& Markin, 2009; Vasbieva et al., 2018).

Digital technology has become an integral part of our lives and the very thing without which most students cannot do. In many cases, the use of technology has become so deeply embedded in everyday life that we do not notice how our lives are changing under the influence of digitalization. Over the past ten years, humanity has seen not only the emergence of a large number of new services and types of services, but the transformation of the usual services (Hague, 2002; Pirogov, 2003; Schwab, 2017). Now many services are changing - there is a departure from the traditional models of provision (offline, via phone, interacting with a person) to the Internet or online model (via the Internet, via smartphone, computer), ranging from taxis and food delivery and ending with public services and banking operations. The concept of consumption can be viewed from different angles. If approached from an etymological point of view, the word consumption is derived from the verb consume, which in turn means to use to meet the needs of spending. In turn, the need is a need, a need for something that requires satisfaction (Ozhegov, 2011).

Consumption - "is an activity without which the history of mankind would be impossible. With the development of society what people consumed changed, how they did it and why, that is, the prerequisites for consumption (Lasinin, 2011; Kalugina \& Tarasevich, 2018; Ovrutsky, 2014; Radaev, 2004, 2005; Tatarintseva, 2016).

Currently, the psychology of consumption is rapidly developing in the framework of marketing and applied research (Gurov \& Baudrillard, 2003; llyin, 2008; Pashkov, 1988; Zhilina \& Frolova, 1969).

The phenomenon of consumption has an impact on the formation of identification images and values of the individual, the functioning and self-development of culture and society, the pace of socio-economic transformation. Consumption in many ways is the system of values and ideas that brings life meanings to satisfy material interests (Bozhovich, 1968; Lazinin, 2011). 
In a broad sense, we can consider digitalization as a modern global trend of economic and social development, which is based on the transformation of information into digital form and leads to an increase in the efficiency of the economy and improve the quality of life (Khalin \& Chernova, 2018). Digitalization is achieved by certain achievements and technological developments in the field of telecommunications - access to communications, the Internet and increase the size of its coverage, as well as in terms of progress in the production of funds.

Overall life satisfaction - digitalization helps to increase the diversity, quality and speed of the services received, increases the security of transactions and personal security when receiving services, and saves time on receiving goods and services and on movement (Belkin, 1991; Bolshakova, 2004; Cherdymova et al., 2019; Goroshko, 2010; Sorokoumova et al., 2019).

One of the most heavily affected areas is e-Commerce. If a few years ago it was possible to book only air tickets with the help of the Internet, now this mechanism of interaction between the seller and the buyer is widespread. There are many interpretations of the concept of $e$ Commerce. In a broad sense, this can be understood as any form of business transactions that are conducted via the Internet. Pirogov (2003) treats e-Commerce as "the technology of commercial operations and production process control using electronic means of data exchange". By providing a platform for services and creating a whole infrastructure, it was possible to simplify the process of obtaining documents, reduce queues in public institutions, and significantly accelerate the process of obtaining services.

\section{MATERIALS AND METHODS}

The purpose of the study: to analyze the practice of student consumption of services in the conditions of their provision digitalization. Two interview guides containing the main interview questions were developed to collect information. Questions relate to the frequency of use of certain services, experience, positive and negative aspects of digital services, with respect to the widespread digitalization of the environment and the changes that bring digital services into everyday life.

- To achieve this goal, the following tasks are set:

- To find out the attitude of students to the use of digital services and the reasons for not using them.

- To find out what services students use most often.

- To examine students' views on the advantages and disadvantages of digitalizing service delivery.

- To find out from students how they relate to the General trend of digitalization.

- To identify how students' daily lives have changed with the advent of digital services.

- To analyze the General opinion of students on the development of the Internet and the increasing introduction of technology in people's lives.

To solve the tasks set in the study, we interviewed students who use the services of taxi, food delivery, Internet banking, online shopping and public services. The first group includes students who are active users of online services, the second group includes students who use the services, but in the traditional form, without resorting to online services and without following the latest technological innovations. 


\section{RESULTS}

Finding out the attitude of informants to the use of digital services and the reasons for refusal to use them we found out what services were used most often, we analyzed the answers to the following questions: what was the reason for the transition from the traditional method of ordering services, how often students use taxi/food delivery services. Based on the answers to the first and second questions we found out:

Students who use online services often purchase (order) something. Most students, who use online services, book a taxi at least 2-3 times a week, a few informants even, use one of the popular applications to order a taxi. All the students from this group said that they had previously ordered a taxi by phone, through the dispatcher, but not as often as now.

Students who are not active users of online services only occasionally buy something online (27\%). Most informants (65\%) said that they buy something inexpensive on the Internet every few months, as "everything is in stores, it's easier for me to just go shopping." Some informants try to avoid buying on the Internet because of the negative experience in the past (12\%).

Speaking about the use of the service for ordering food, the majority of students (63\%) indicated that they used this online service 1-2 times a week; the rest used this service more often-3-4 times a week (37\%). They noted the large selection of food in various applications, the speed of delivery and the quality of food. Among informants who do not use online services, the frequency of orders per week is lower - more than half (62\%) of informants reported that they ordered food by phone several times a month, the rest of the informants - once a month. In most cases, the reluctance to use online delivery is due to trusted locations or negative app experience (12\%). In addition, half of the informants noted that often the prices in the applications were higher, compared with the order directly through the phone.

It turned out that in addition to ordering food and taxis, students used digital banking services. Among all online users surveyed, each person used online banking for his or her own personal purposes. Among informants who do not use online services in General, almost half (56\%) have the Sberbank Online application, but use it very rarely, only in cases when it is the only way to get money from another person/company. Interestingly, these informants almost immediately use ATM to withdraw cash. Other informants from this group do not use online banking. Several informants have used this service in the past, but have decided to stop. As the interview progressed, there was some distrust to online banking and banks in General.

The majority of students who use online services reported that they bought something online once a week (72\%). Other informants reported that they made purchases online once a month. Among the popular purchases, there were various household goods and clothing (28\%).

Many informants from both groups buy tickets for transport and various events online. In the group with active users of online services, almost all buy tickets regularly, and in the group, where they adhere to ways that are more traditional, half buys various tickets on a regular basis. The rest do it at the box office or special agencies.

When it came to such a platform as public Services - students noted that they were users of this platform. This service is used to pay fines and obtain various documentation. On the request to compare the experience of receiving these services in the past and now - all students noted great improvements in the quality and speed of receiving services.

Having solved the tasks, in General, we can say that the group, which actively uses digital services, has a positive attitude towards them. For the most part, the informants noted only the 
positive aspects of the use of digital services, almost without any mention of shortcomings. Services that are now on the market fully satisfy the needs of users. If we talk about a group in which informants are not active users of online services and adhere to traditional methods, it is worth noting some dissatisfaction with the use of modern methods of obtaining services. Almost every informant had some experience of using online services, but the result was negative (12\%). Informants are distrustful of new methods of obtaining services, especially when it comes to any operations related to money. There is a feeling that the online services provided are of poor quality, and informants are ready to experience some discomfort in exchange for the usual, guaranteed and high quality, in their opinion, service. Some informants noted that it was not easy for them to adapt to new technologically advanced things, but the rest of the informants believed that they could adapt to innovations, but the way of providing services, that was perceived as traditional and was most acceptable to them.

Speaking about what services are used most often, a clear leader is to order a taxi - all students to some extent use them. Food delivery service and only then online banking, online shopping and public services follow this. This can be explained by the degree of need for services in everyday life - transport is an integral part of the life of a person living in the city. Despite the fact that public services are used by absolutely all students, such services are used less often, since the need to carry out any operations with documents or registrations occurs much less frequently than more usual household things.

Studying the opinion of informants about what are the advantages and disadvantages of digitalization of services, we have noted that among the advantages are the convenience of using online interfaces on mobile devices and the speed of obtaining services, this can be applied to all areas. We can say that with the advent of digitalization in terms of the provision and consumption of services, the amount of time spent on interaction with the agent or the interface of the service has decreased. In most cases, the role of the real person in the provision of services is reduced to a minimum, everything is built on algorithms and the person is needed only when there is a problem in obtaining the service, which happens very rarely. Among the shortcomings, it is noted that some services are not fully technically improved, that is, there are some mistakes and errors that prevent the receipt of services in the proper quality, but such situations are rare, only a few informants were able to mention any negative experience. Students, who do not use online services actively, noted that in many cases preferred to interact with a real person, because even if there was a problem or not docking - everything could be quickly solved.

\section{DISCUSSIONS}

Now humanity lives in a world where new technology so deeply penetrates into the everyday life that the world and life around us is changing at a tremendous pace. Just 15 years ago, it was impossible to imagine how our environment would look like. With the advent of affordable mobile Internet and devices, users have discovered new opportunities to communicate with each other, as well as effectively interact with the world around them. Moreover, the way that people do the usual things in the field of services has changed. With the advent of digitalization, the methods of providing and receiving services have changed. If earlier it was necessary to call, interact with real people or physically be at the destination, now almost all the services that may ever be needed by a person are available through a smartphone with mobile Internet available to a large number of people.

How the intake itself looks like now and how the service delivery methods have changed? Consumption itself is studied not so long ago. We studied the prerequisites for the phenomenon of consumption, formed under the influence of society, how and what people spend money and 
various ideological approaches to consumption. Now companies that are engaged in marketing and technological developments are making great progress in this area. They study the current state of digitalization and the introduction of technology into everyday life.

\section{CONCLUSION}

Students, who are active users of online services, often order and buy anything in General. Most members of this group order a taxi several times a week, arrange food delivery several times a week, regularly use banking services, often buy tickets, actively buy goods in stores - and all this is done using online methods: most often it happens with a smartphone with Internet access, rarely from a computer. This behavior is caused by the convenience of the services provided. Every year there are improvements and innovations in the way people interact with the companies that provide these services. If we compare how the methods of provision have changed compared to traditional methods, the students noted the convenience, speed and more free time. In terms of convenience, it was seen a comfortable application interface and ease of use. In terms of speed, the informants noted that it had become much faster to carry out the tasks that they needed. When talking about increasing the amount of free time, the informants noted that now they spent less time to receive a particular service, and felt more confident and relaxed, going through the process of obtaining services online.

If we talk about the second group, the overall activity is lower compared to the first group. Students use the same practical services, but without resorting to modern online methods. They buy less goods, order less food, taxis, and tickets and use minimal banking services. Among the students we noticed a distrust to modern services, which was based either on the previous negative experience of use, or on the unsatisfactory experience of friends. They believe that those methods and applications that are now on the market are not optimal for them and the usual methods of obtaining services for them remain more comfortable and familiar, even despite the greater amount of time spent on obtaining a particular service.

It is worth noting one type of service used by informants in all groups - public services. Over the past few years, the service has gone through a huge number of improvements and has become even more effective convenient and clear that even students who do not trust most online services are actively using public services online. Students noted the convenience of the services provided - everything can be arranged online, all the information is quite clear; and as for the speed of receipt -there are no queues, everything as quickly as possible compared to how it was before. Regarding the attitude to General digitalization and the increasing introduction of technology in everyday life, active users perceive this trend positively, believing that all innovations are beneficial. Among the users of traditional methods, the attitude to this is more neutral. They recognize that there are positive aspects of this trend and progress is unstoppable, but they are still skeptical about everything that is happening. While the first group can hardly imagine life without the Internet and existing technologies, the second group is more relaxed about the lack of a large number of technologies around them. Despite all the progress that is happening now, the development of technologies and their implementation in everyday life, the use of online services is still not a universal and proven method for all people in obtaining a particular service. There is an active group of users of online services, which is growing every year, but there is also a significant proportion of students who are not satisfied with the current state of Affairs in terms of providing online services and they still prefer the traditional method due to discomfort and some distrust in the methods of providing services. Although it is worth noting that most of the students in this group do not deny the possibility of transition to modern methods of providing services online. 


\section{REFERENCES}

Alisov, E. A, Cherdymova, E. I., Trubina, G. F., Yakushev, A. N., Zhdanov, S. P., Popova, O. V., \& Kobzar-Frolova, M. N. (2018). Study of Dominant Type of Student Ecological Focus. Ekoloji 27(106), 357-362.

Belkin, A. S. (1991). Success Situation: how to create it. Moscow: Prosvescheniye.

Bolshakova, O. A. (2004). Modern priorities in the daily life of students: University studies and paid work. Values of daily activities of citizens. Moscow: Moscow Institute of sociology RAS.

Bozhovich, L. I. (1968). Personality and its formation in childhood. Moscow: Press.

Cherdymova, E. I., Afanasjeva, S. A., Parkhomenko, A. G., Ponyavina, M. B., Yulova, E. S., Nesmeianova, I. A., \& Skutelnik, O. A. (2018). Student ecological consciousness as determining component of ecological-oriented activity. Eurasian Journal of Biosciences, 12(2), 167-174

Cherdymova, E. I., Prokopyev, A. I., Karpenkova, T. V., Pravkin, S. A., Ponomareva, N. S., Kanyaeva, O. M., Ryazapova, L. Z., \& Anufriev, A. F. (2019). EcoArt Therapy as a Factor of Students' Environmental Consciousness Development. Ekoloji, 28(107), 687-693.

Goroshko, E. I. (2010). Communicative space of the Internet as an object of socio-cultural analysis. Bulletin of Odessa national University. Odessa, 15(14), 130 - 136.

Gurov, O. N., \& Baudrillard, J. (2003). Approaches to the study of consumer culture. Moscow: AST.

Hague, M. (2002). Fundamentals of e-business. Moscow: FAIR-PRESS.

Ilyin, V. I. (2008). Consumption as a discourse. St. Petersburg: Intersocis.

Kalugina, O. A., \& Tarasevich, N. A. (2018). Smart technology integration into EFL teaching at the $\begin{array}{llll}\text { non-linguistic higher school. } \quad \text { XLinguae, } & 11(1 \mathrm{XL}),\end{array}$ https://doi.org/10.18355/XL.2018.11.01XL.02

Khalin, V. G., \& Chernova, G. V. (2018). Digitalization and its impact on the Russian economy and society: advantages, challenges, threats and risks. Retrieved on 21 April 2019 from https://cyberleninka.ru/arti-cle/n/tsifrovizatsiya-i-ee-vliyanie-na-rossiyskuyu-ekonomiku -i-obschestvo-preimuschestva-vyzovy-ugrozy-i-riski

Lazinin, I. V. (2011). Consumption as a cultural phenomenon: modern specific. Bulletin of Stavropol state University. Philosophy science, 76, 18-25.

Ovrutsky, A. V. (2014). Sociology of consumption: main directions of research. Rostov-on-Don: Southern Federal University.

Ozhegov, S. I. (2011). Dictionary of Russian language. Moscow: World and Education, Onyx.

Pashkov, A. S. (1988). The Way of life of a large city population: a comprehensive social studies. Leningrad: Publishing house of Leningrad state University.

Pirogov, S. V. (2003). E-Commerce. Moscow: Publishing House "Social relations", publishing House "Perspektiva". 
Radaev, V. V. (2004). Economic sociology in Russia: formation and development. Economic sociology, 5(3), 98-104. https://doi.org/10.17323/1726-3247-2004-3-94-109

Radaev, V. V. (2005). Sociology of consumption: basic approaches. Sociological research, NRU HSE, 1, 12-25.

Radaev, V. V., Kotelnikova, Z. V., \& Markin, M. E. (2009). Development of Russian retail: measures of state regulation and their consequences. Analytics of Laboratory for studies in economic sociology. Moscow: Publishing house of the HSEp.

Schwab, K. (2017). The Fourth industrial revolution. Moscow: Eksmo.

Sorokoumova, E. A., Cherdymova, E. I., Rezvantseva, M. O., Kochneva, L. V., Latysheva, V. V., \& Perkova, E. P. (2019). Environmental and Social Practices of Old Stuff Use and Disposal by Students. Ekoloji, 28(107), 5065-5069.

Tatarintseva, Yu. O. (2016). Consumer Culture as a sociological category. Bulletin of TSU, Series of social Sciences, 3(7), 66-76.

Vasbieva, D. G., Sokolova, N. L., Masalimova, A. R., Shinkaruk, V. M., \& Kiva-Khamzina, Y. L. (2018). Exploring the EFL teacher's role in a smart learning environment - a review study. XLinguae, 11(2), 265-274. https://doi.org/10.18355/XL.2018.11.02.21

Zhilina, L. N., \& Frolova, N. T. (1969). Problems of consumption and education of personality. Moscow: Mysl.

Correspondence: Almira R. Bayanova, Postgraduate Student of the Institute of Psychology and Education, Kazan (Volga region) Federal University, Kazan, Russia, and Lecturer in Technical College of Kazan National Research Technical University named after A.N. Tupolev - KAI, Kazan, Russia. E-mail: almira-djl@mail.ru 